\title{
Altered Regulation of CREB by Chronic Antidepressant Administration in the Brain of Transgenic Mice with Impaired Glucocorticoid Receptor Function
}

Joan M.C. Blom, Ph.D., Fabio Tascedda, Ph.D., Serena Carra, M.S., Chiara Ferraguti, M.S., Nicholas Barden, Ph.D., and Nicoletta Brunello, Ph.D.

Various effects of antidepressant drugs on gene transcription have been described and altered gene expression has been proposed as being a common biological basis underlying depressive illness. One target for the common action of antidepressants is a modifying effect on the regulation of postreceptor pathways and genes related to the $C A M P$ cascade. Recent studies have demonstrated that long-term antidepressant treatment resulted in sustained activation of the cyclic adenosine 3',5'-monophosphate system and in increased expression of the transcription factor $c A M P$ response element binding protein (CREB). A transgenic animal model of depression with impaired glucocorticoid receptor function was used to investigate the effect of chronic antidepressant treatments on CREB expression in different brain areas. Wild-type and transgenic mice received one administration of saline, desipramine, or fluoxetine, daily for 21 days. The effects of antidepressants on CREB $m R N A$ were analyzed using a sensitive RNase protection assay. Antidepressant treatment resulted in a neuroanatomically and animal specific expression pattern of CREB. Our findings suggest that life-long central glucocorticoid receptor dysfunction results in an altered sensitivity with respect to the effects of antidepressants on the expression of CREB.

[Neuropsychopharmacology 26:605-614, 2002] (C) 2002 American College of Neuropsychopharmacology. Published by Elsevier Science Inc.
From the Department of Psychology, Università Vità-Salute San Raffaele, Via Olgettina 58, Milan, Italy (JMCB), Department of Pharmaceutical Sciences, University of Modena and Reggio Emilia, Via Campi 183, 41100 Modena, Italy (JMCB, FT, SC, CF, NBr), Department of Neuroscience, CHUQ pavillon CHUL, and Department of Anatomy and Physiology, Laval University 2705 Blvd Laurier, Ste Foy, Quèbec, Canada (NBa).

Address correspondence to: Joan M.C. Blom, Department of Pharmaceutical Sciences, University of Modena and Reggio Emilia, Via Campi 183, 41100 Modena, Italy, Tel.: +39.059-2055163, Fax: 39.059-2055131, E-mail: blom@mailserver.unimi.it

Received July 5, 2001; revised October 18, 2001; accepted October 26, 2001.

Online publication: 10/30/01 at www.acnp.org/citations/ Npp103001196.
KEY WORDS: CREB; Antidepressant drugs; Glucocorticoid receptor; Transgenic mice

While the regulation of monoamine levels and their receptors or the restoration of hypothalamus-pituitaryadrenal (HPA) system feedback may represent initial effects of antidepressant drugs, their therapeutic action could be related to subsequent action on genes involved in postreceptor mechanisms. One such postreceptor target that can be influenced by either $5 \mathrm{HT}$ or NE as well as by drugs that affect these systems is the nuclear transcription factor cAMP response element binding protein (CREB) (Montminy, et al. 1990; Meyer and Habener 1993; Nibuya et al. 1996; Duman et al. 1997, 1999; Thome et al. 2000). A role for the cAMP cascade in the long-term ac- 
tion of antidepressant treatment is supported by research showing that chronic administration of antidepressants regulates brain levels of adenylyl cyclase (Ozawa and Rasenick 1991) and PKA (Nestler et al. 1989) and that the activity of CREB is enhanced following its phosphorylation by PKA (Meyer and Habener 1993; Ghosh and Greenberg 1995). Furthermore, viral mediated over-expression of CREB in two animal models of depression produced an antidepressant effect and resulted in improved behavioral performance in both models (Chen et al. 2001).

Based on the hypothesis that the apparent lack of sensitivity to corticosteroids observed in major depression is causally linked to the pathogenesis of depression (Holsboer and Barden 1996; Holsboer 2000; Pariante and Miller 2001) as well as to the therapeutic effectiveness of antidepressant drugs (Barden 1996), a transgenic animal model of neuroendocrine changes associated with depression was developed (Pepin et al. 1992a). Insertion into the mouse genome of a transgene expressing antisense RNA complementary to a fragment of the glucocorticoid receptor (GR) cDNA produced an animal with a defect in the neuronal glucocorticoid receptors that mediate the effects of high "stress" levels of glucocorticoids on the negative feedback of the HPA system. These transgenic mice displayed impaired endogenous GR function and were characterized by dysfunctional glucocorticoid inhibitory feedback and disturbed ACTH and corticosterone secretory responses (Barden et al. 1997; Karanth et al. 1997; Dijkstra et al. 1998). Long-term treatment of the transgenic mice with antidepressant drugs caused an increase in GR gene expression and produced significant normalization of the HPA system hyperactivity through restoration of functional glucocorticoid inhibitory feedback (Pepin et al. 1992b; Barden et al. 1995; Barden et al. 1997).

Because the second messenger cyclic AMP plays a central role in signaling within the HPA axis, long-term adaptations in cAMP regulated gene expression are critical to chronic HPA dysfunction (Hatalski and Baram 1997). Given that depressed patients display reduced cAMP protein kinase activity (Shelton et al. 1996) and that the cAMP/PKA cascade is involved in mediating the action of antidepressant drugs, GR dysfunction and disruption of proper cAMP/PKA signaling both observed in depression are highly interdependent. The use of this transgenic animal model allowed study of the effectiveness of chronic antidepressant treatment in restoring long-term defective glucocorticoid feedback inhibition and dysregulation of the HPA system by affecting gene expression crucial to the cAMP-signaling pathway.

Consequently, we tested the hypothesis that upregulation of CREB is an important factor in the therapeutic action of antidepressant drugs. This role for CREB, that provides a common intracellular adaptation for the action of diverse types of antidepressants, was tested in various

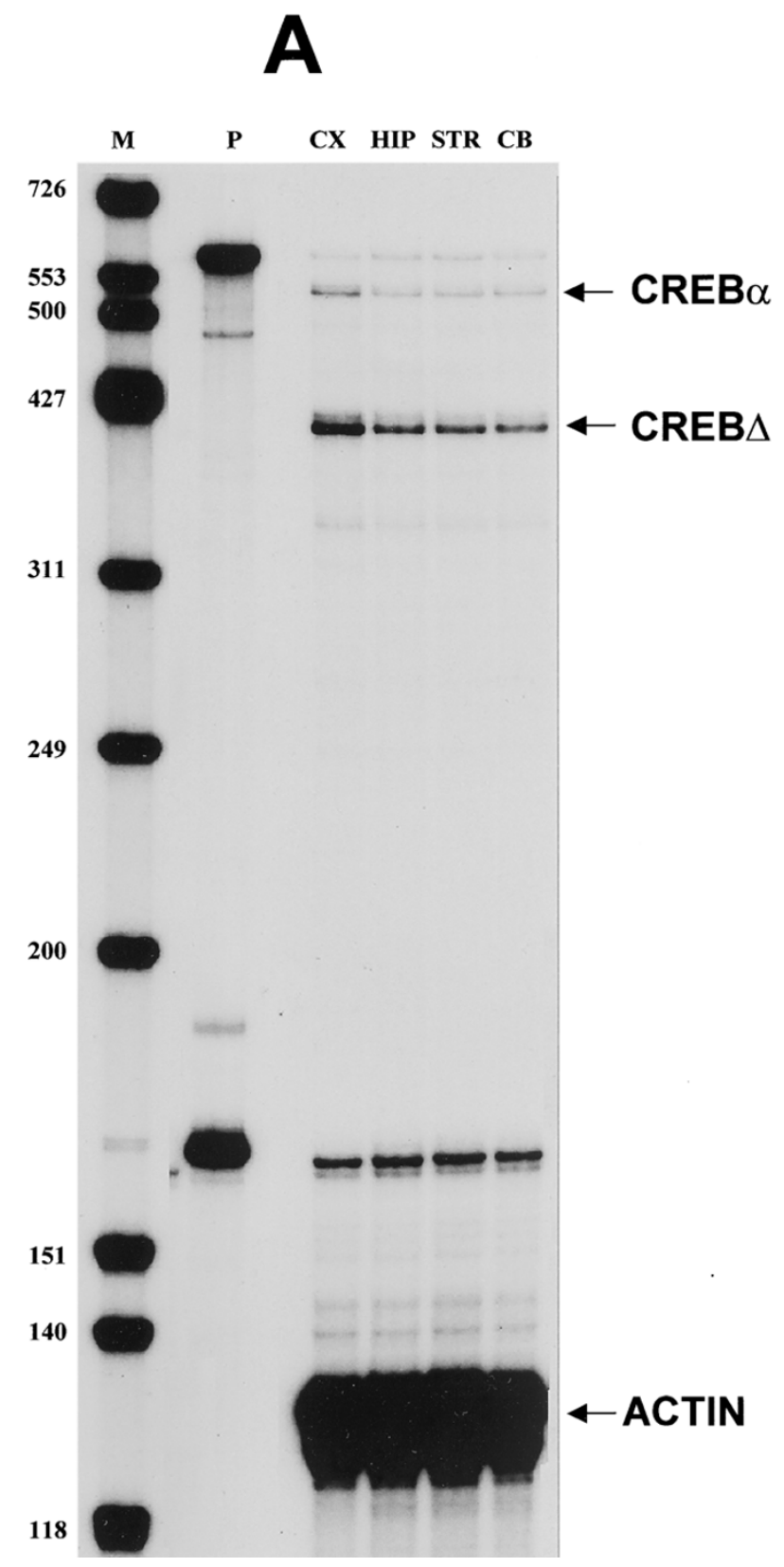

Figure 1. Panel A: Representative autoradiography of an RNase Protection Assay indicating the distribution of CREB- $\alpha$ and CREB- $\Delta$ in different brain areas. $10 \mu \mathrm{g}$ of total RNA was used in each lane with M: molecular standard; P: Probe; CX: cortex; HIP: hippocampus; STR: striatum; and CB: cerebellum. The lane marked as probe indicates an aliquot $(8000 \mathrm{cpm})$ of the hybridization solution containing the antisense cRNA probes to CREB- $\alpha$, CREB- $\Delta$, and $\beta$-actin. The $X$-ray film was exposed for $16 \mathrm{~h}$ at $-70^{\circ} \mathrm{C}$ with an intensifying screen. In all areas analyzed, CREB- $\Delta$ expression was 4-5 times higher then CREB- $\alpha$, with both isoforms expressed most in the cortex. Panel B: Basal mRNA expression of CREB- $\alpha$ and CREB- $\Delta$ in the hippocampus and cortex of transgenic and wild-type mice. Levels of CREB- $\alpha$ and CREB- $\Delta$ mRNA were determined by RNase Protection Assay. No difference was observed in $\beta$-actin expression. The results are expressed as the mean \pm S.E.M. of 6-8 mice in each experimental group. 


\section{B}

\section{CREB $\alpha$}
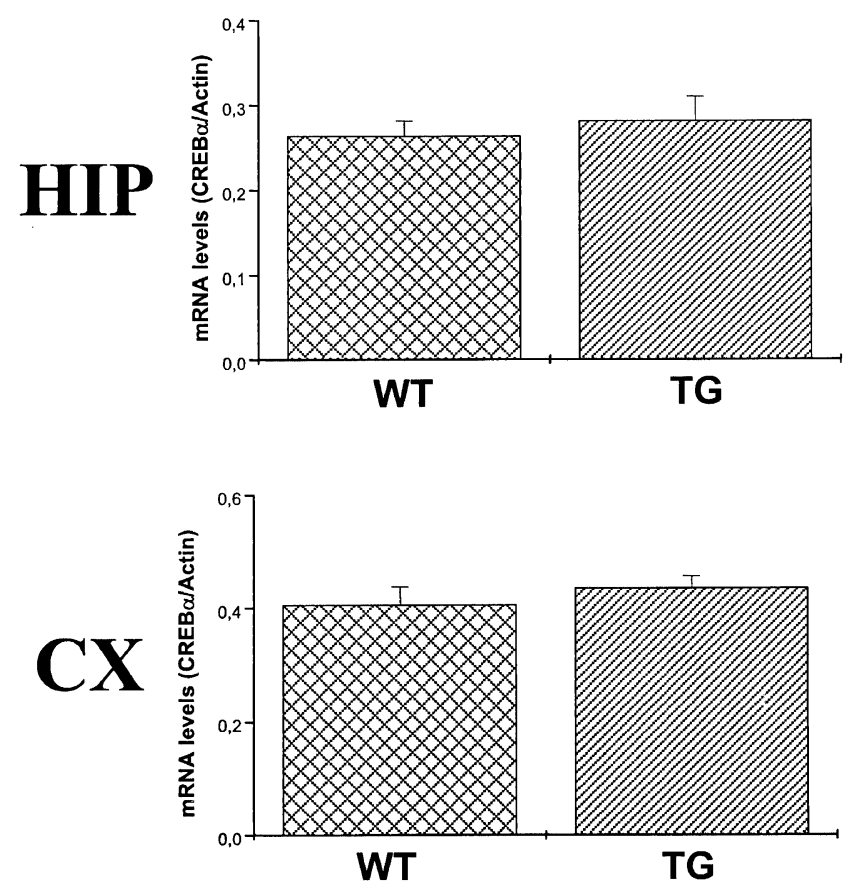

TG

\section{CREB $\Delta$}
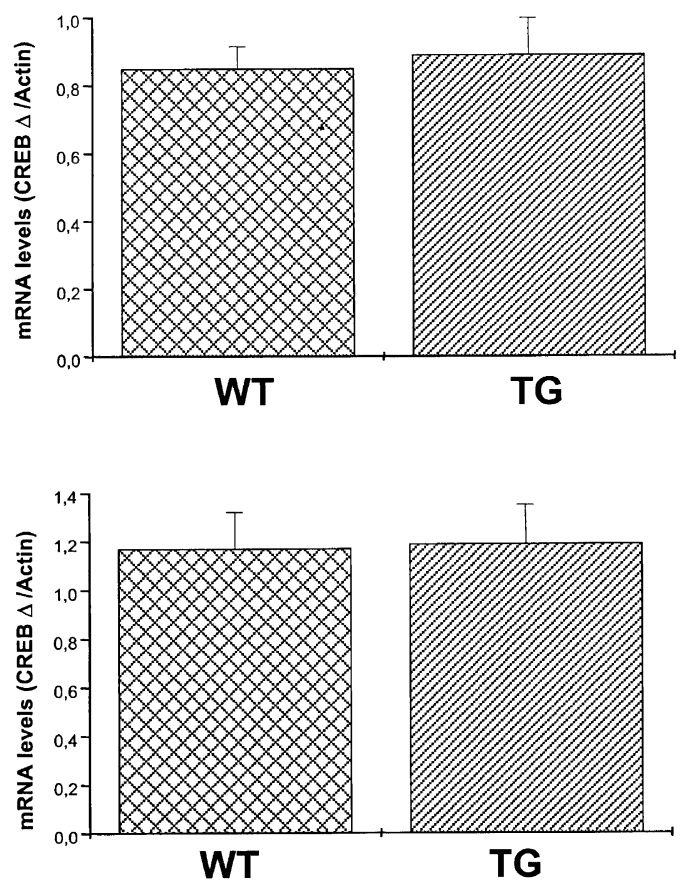

Figure 1. (Continued)

brain structures using both normal and transgenic mice known to be sensitive to antidepressant action.

\section{METHODS}

\section{Animals}

Adult transgenic (TG) mice (line 5.4) bred and raised in our colony and non-transgenic wild-type (WT) mice (B6C3F1) (Charles River Laboratories, Como) were used in this study. Transgenic mice were maintained as homozygotes. They were constructed using oocytes from B6C3F1 females. All transgenic mice were checked for transgene presence before entering an experiment and all mice were found to be homozygous. Animals were housed in pairs in polycarbonate cages $(28 \times 17 \times 12 \mathrm{~cm})$ with ad libitum access to food and tap water throughout the study, and maintained under a 12:12 light-dark cycle in an ambient temperature of $21 \pm 3^{\circ} \mathrm{C}$, relative humidity uncontrolled.

\section{Treatment Protocol}

TG and WT mice received daily i.p. injections with desipramine $(10 \mathrm{mg} / \mathrm{kg} \mathrm{BW})$, fluoxetine $(10 \mathrm{mg} / \mathrm{kg} \mathrm{BW})$ or vehicle for a period of 21 days. Six experimental groups were used with six animals in each group.

\section{RNA Preparation}

The tissue from different brain structures was homogenized in $4 \mathrm{M}$ guanidinium isothiocyanate (containing 25 $\mathrm{mM}$ sodium citrate $\mathrm{pH} 7.5,0.5 \%$ sarcosyl and $0.1 \%$ 2-mercaptoethanol) and total RNA was isolated by phenol-chloroform extraction (Chomczynski and Sacchi 1987). Quantification was carried out by absorption at $260 \mathrm{~nm}$ and RNA was reprecipitated in ethanol for RNase protection assay. In order to verify that equal amounts of total RNA were used in the RNase protection assay, parallel samples were loaded on agarose/formaldehyde gel, run (35V for $16 \mathrm{~h}$ ) and stained with ethidium bromide (not shown).

\section{CREB Probe Preparation}

The cDNA (530 bp EcoRI- StuI fragment) for mouse CREB was subcloned into pBluescript sk- (Stratagene), in order to obtain a template for the in vitro transcription of cRNA probes to be employed in the RNase protection assay. cRNA probes were generated using T7 RNA polymerase and ${ }^{32} \mathrm{P}-\mathrm{CTP}$ was used as the radiolabeled nucleotide. The cRNA probe for CREB had 570 bases and after digestion generated two major protected fragments one of 530 bases, CREB- $\alpha$, and one of 403 bases, CREB- $\Delta$. pTRI-actine (Ambion) containing a portion of $\beta$-actine cDNA was utilized as internal stardard. The probe for actin was gener- 


\section{A}
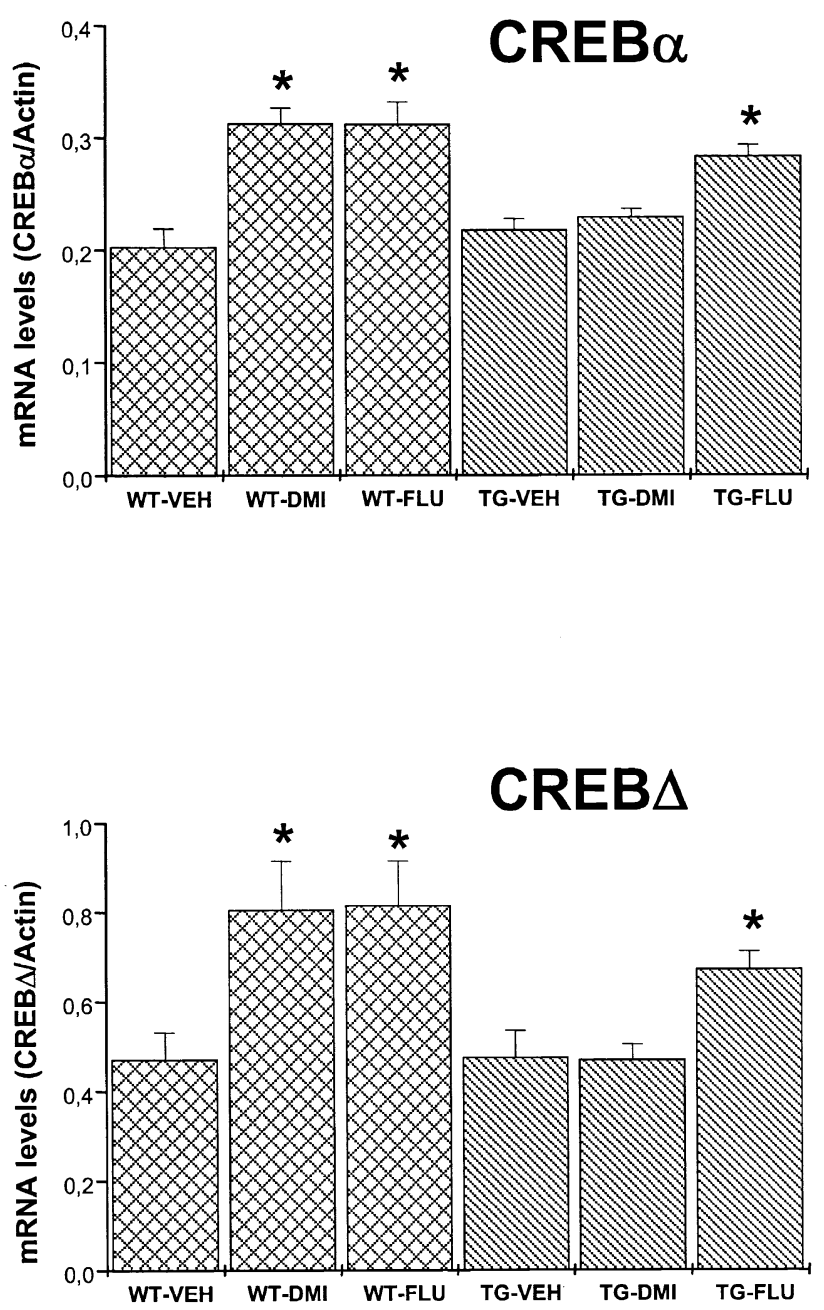

Figure 2. Panel A: mRNA expression of CREB- $\alpha$ and CREB- $\Delta$ in the hippocampus of transgenic and wild-type mice after treatment with antidepressant drugs. Levels of CREB- $\alpha$ and CREB- $\Delta$ mRNA were determined by RNase Protection Assay. The results, normalized for actin, are expressed as the mean \pm S.E.M. of $6-8$ mice in each experimental group. ${ }^{*} p<$ .05 compared with WT controls. Panel B: Representative RNase protection assay of CREB transcripts in the hippocampus of transgenic and wild-type mice after treatment with antidepressant drugs.

ated using T3 RNA polymerase, had 160 bases, and generated a protected fragment of 125 bases.

\section{RNase Protection Assay}

The RNase protection assay was performed on a $10 \mu \mathrm{g}$ sample of total RNA. Briefly, after ethanol-precipitation, total RNA obtained from different tissues was dis- solved in $20 \mu \mathrm{l}$ of hybridization solution (80\% formamide, $40 \mathrm{mM}$ PIPES $\mathrm{pH} 6.4,400 \mathrm{mM}$ sodium acetate $\mathrm{pH}$ 6.4 and $1 \mathrm{mM}$ EDTA) containing 150,000 cpm of each ${ }^{32} \mathrm{P}$-labeled cRNA probe (specific activity $>10^{8} \mathrm{cpm} /$ $\mu \mathrm{g})$. After being heated at $85^{\circ} \mathrm{C}$ for $10 \mathrm{~min}$, the cRNA probes were allowed to hybridize to the endogenous RNAs at $45^{\circ} \mathrm{C}$ overnight. At the end of the hybridization, the solution was diluted with $200 \mu$ l of RNase digestion buffer (300 mM NaCl, $10 \mathrm{mM}$ Tris $\mathrm{HCl} \mathrm{pH} 7.4,5$ $\mathrm{mM}$ EDTA $\mathrm{pH}$ 7.4) containing a 1/200 dilution of a RNase cocktail (1 g/1 RNase A and 20 U/1 RNase T1) and incubated for $30 \mathrm{~min}$ at $30^{\circ} \mathrm{C}$. Proteinase $\mathrm{K}(10 \mu \mathrm{g})$ and SDS (10 $\mu \mathrm{l}$ of $20 \%$ stock solution) were than added to the sample and the mixture was incubated at $37^{\circ} \mathrm{C}$ for an additional $15 \mathrm{~min}$. At the end of the incubation the sample was extracted with phenol/chloroform and ethanol precipitated. The pellet, containing the RNA:RNA hybrids was dried and resuspended in loading buffer (80\% formamide, $0.1 \%$ xylene cyanol, $0.1 \%$ bromophenol blue, $2 \mathrm{mM}$ EDTA), boiled at $95^{\circ} \mathrm{C}$ for $5 \mathrm{~min}$ and separated on a $5 \%$ polyacrylamide gel under denaturing conditions (7M urea). The protected fragments were visualized by autoradiography and their size determined by the use of ${ }^{32} \mathrm{P}$-end-labeled (T4 polynucleotide kinase) DNA phiX174-digested Hinf-I fragments.

\section{RNA Calculation}

The levels of mRNA were calculated by measuring the peak densitometric area of the autoradiography analyzed with an image analyzer (GS 690 BIORAD). In order to ensure that the autoradiographic bands were in the linear range of intensity, different exposure times were used.

\section{Statistical Analysis}

Statistical evaluation of the changes in mRNA levels was performed using an analysis of variance (ANOVA). Significant changes were determined by Dunnett $t$-test.

\section{RESULTS}

CREB is ubiquitously expressed in the CNS of mice and the highest levels of CREB were found in the cortex, the hippocampus, striatum, and cerebellum. Basal expression of CREB mRNA in both hippocampus and cortex did not differ between WT and TG mice (Figure 1, Panels A and B). While no difference was observed in the hippocampus and cortex of TG and WT mice in the expression of the two isoforms of CREB, CREB- $\alpha$ and CREB- $\Delta$, the level of expression of the two isoforms did differ in the cortex and hippocampus as well as in the striatum and cerebellum (Figure 1, Panel B). In all areas analyzed, and irrespective of the type of animal, CREB- $\Delta$ expression was 4-5 times higher then CREB- $\alpha$. 
B

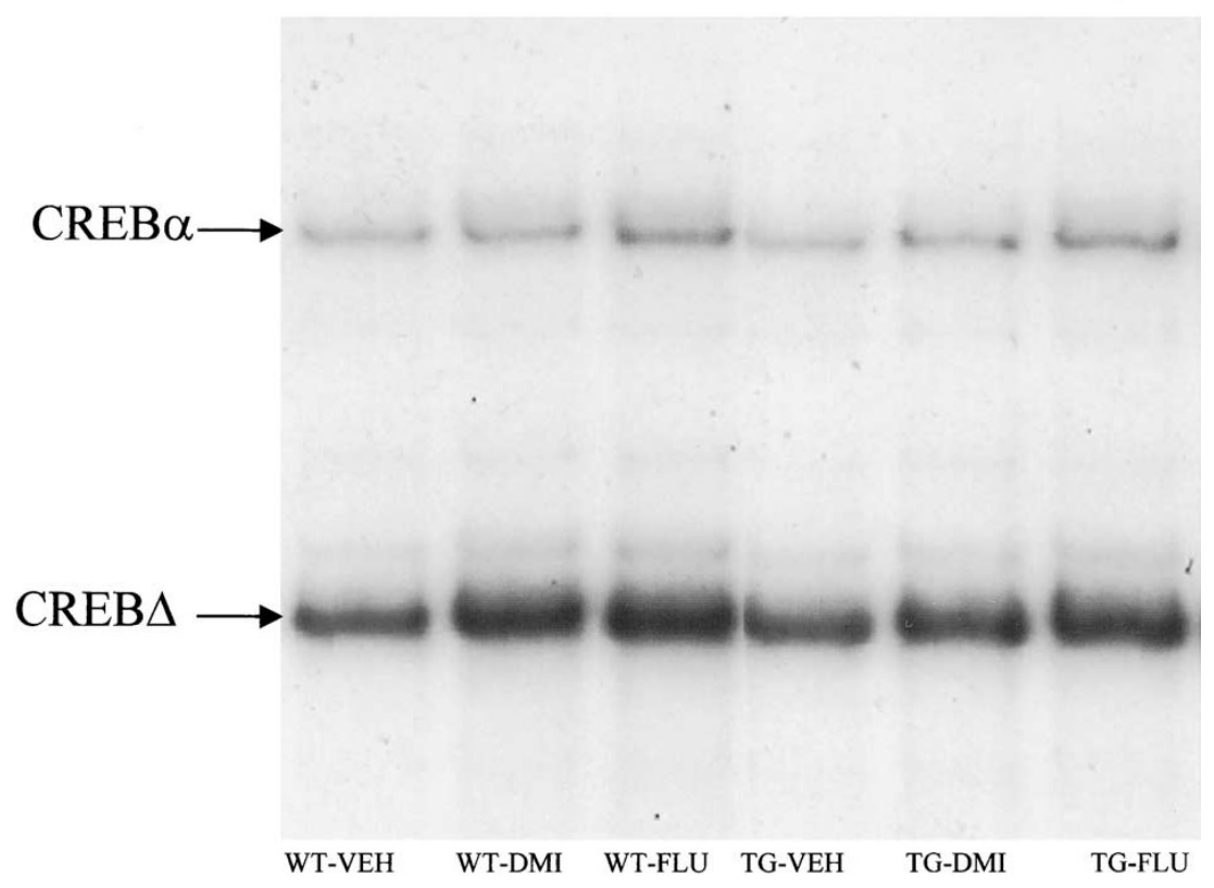

Figure 2. (Continued)
Following chronic administration of antidepressant drugs brain area specific upregulation of CREB- $\alpha$ and CREB- $\Delta$ mRNA was displayed. Chronic treatment (21 days) with desipramine (a selective NE reuptake inhibitor) and fluoxetine (a 5-HT selective reuptake inhibitor) increased the expression of CREB- $\alpha$ and CREB- $\Delta$ mRNA in the hippocampus of wild type mice (Figure 2, Panels $A$ and $B$ ). In transgenic mice, CREB expression in the hippocampus was enhanced only by fluoxetine but not by desipramine. Acute treatment with desipramine or fluoxetine did not affect CREB gene expression in the hippocampus (data not shown).

Chronic treatment with desipramine significantly enhanced levels of CREB- $\alpha$ and CREB- $\Delta$ in the cortex of TGmice but not in wild type mice (Figure 3, Panels A and B).

To determine the area-specific effects of antidepressant drugs on CREB gene expression, other distinct regions of the brain of WT and TG mice were analyzed after long-term treatment with desipramine and fluoxetine. No differences between WT and TG mice were found in the basic expression of CREB- $\alpha$ and CREB- $\Delta$ in the cerebellum, striatum and hypothalamus. Furthermore, CREB expression in these brain regions was not affected by chronic antidepressant treatment (Table 1).

\section{DISCUSSION}

Depression is an heterogeneous illness that can result from the dysfunction of one or several neurotransmitter or metabolic systems resulting from a combination of genetic and environmental factors. The cAMP cascade is one of many intracellular pathways regulated by serotonin and NE that could be important for antidepressant action and the present experiments focused on the significance of the cAMP-signaling pathway in a model of a chronically disturbed HPA system that can be normalized by antidepressant drug treatment. The goal of the study was 2-fold: (1) to test whether defective glucocorticoid feedback inhibition of the HPA system leads to changes in the expression of cAMP response element binding protein; and (2) to determine whether or not antidepressant drug treatment affects CREB gene expression in vivo.

Three main conclusions arose from our experiments: First, chronic disruption of GR-gene expression leading to defective regulation of the HPA system did not alter basal expression of CREB mRNA in distinct brain regions. Second, the antidepressant drugs desipramine and fluoxetine differentially affected CREB gene expression in WT as compared with TG mice. Chronic antidepressant treatment resulted in brain region-specific upregulation of CREB gene expression according to the type of animal. Third, life-long central glucocorticoid receptor dysfunction resulted in altered sensitivity of CREB expression to antidepressant drugs.

Altered glucocorticoid receptor signaling could be a crucial mechanism in the pathophysiology underlying depression (Holsboer and Barden 1996; Holsboer 2000; Pariante and Miller 2001) and selective reduction of glu- 


\section{A}
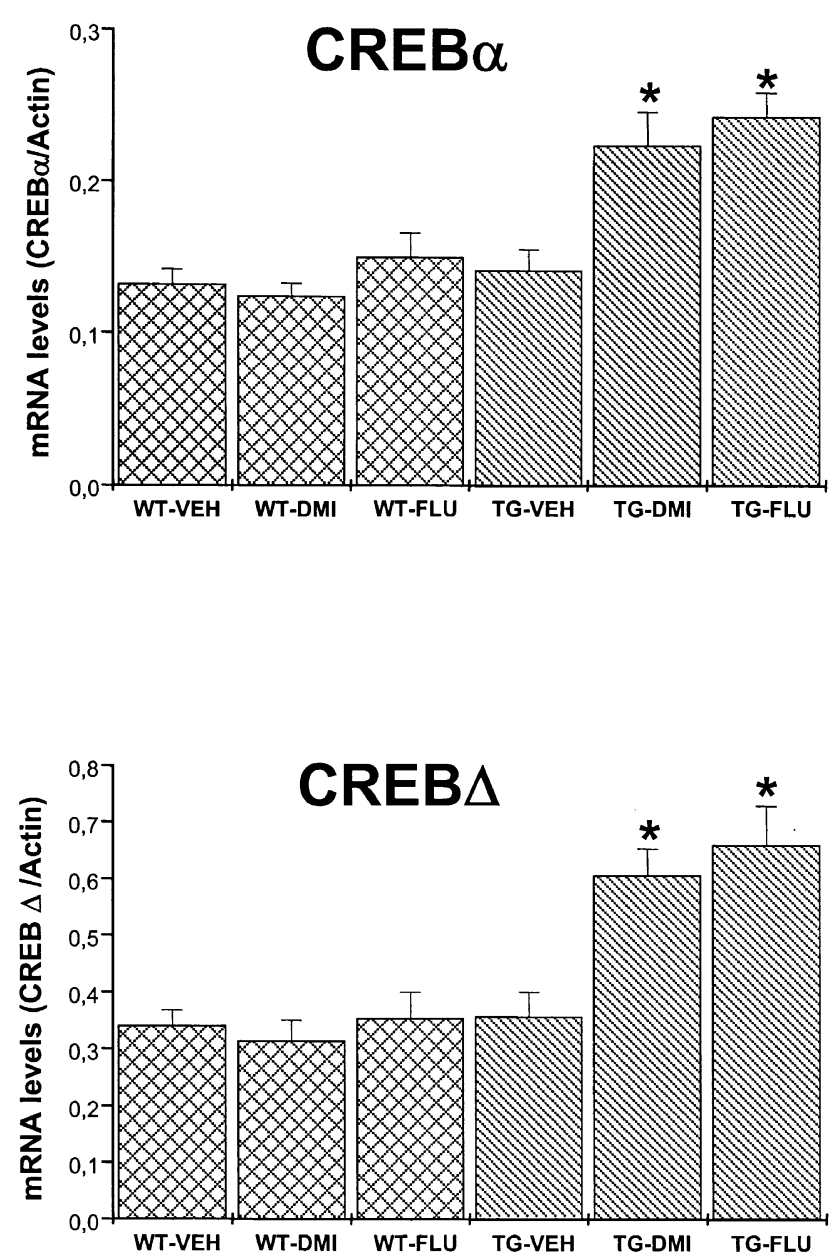

Figure 3. Panel A: mRNA expression of CREB- $\alpha$ and CREB- $\Delta$ in the cortex of transgenic and wild-type mice after treatment with antidepressant drugs. Levels of CREB- $\alpha$ and CREB- $\Delta$ mRNA were determined by RNase Protection Assay. The results, normalized for actin, are expressed as the mean \pm S.E.M. of 6-8 mice in each experimental group. ${ }^{*} p<$ .05 compared with WT controls (ANOVA). Panel B: Representative RNase protection assay of CREB transcripts in the hippocampus of transgenic and wild-type mice after treatment with antidepressant drugs.

cocorticoid receptor activity in transgenic mice lead to changes in the HPA system similar to those observed in patients suffering from major depression. (Barden et al. 1997; Karanth et al. 1997). Furthermore, modifications in the cAMP cascade play an important role in the pathogenesis of major depression and in the regulation of the HPA axis. cAMP-dependent transcription factors, including CREB, a nuclear protein substrate that binds to a cAMP response element (CRE) present in the promoter region of a variety of genes, are central to a promising new hypothesis linking alterations in cAMP activation to depression and the action of antidepressant drugs. These transcription factors, in response to cAMP, can also modulate the expression of genes involved in the HPA axis. The first part of the present study, therefore, focused on the question of whether transgenic mice with altered HPA regulation and impaired GR function display altered basal expression of CREB. No such differences were found and GR dysfunction did affected neither the absolute nor the relative (vs. WT) amounts of CREB mRNA in the cortex and hippocampus of transgenic mice. High, non-basal, levels of ACTH and a blunted circadian hormonal rhythm characteristic of these transgenic mice were not sufficient to modify basal CREB expression.

CREB and related CRE-binding proteins are normally present in their non-phosphorylated form and their activity can be regulated through phosphorylation. The amount of P-CREB is probably more important for transcriptional activation than the absolute amount of CREB (Gonzalez and Montminy 1989; Sassone-Corsi 1995; Lamas and Sassone-Corsi 1997). Consequently, differences, in basal levels of CREB gene expression may not be a constitutive feature of central HPA axis dysfunction. In addition, the complexity of the regulation of CREB becomes evident when the elevated numbers of signal transduction pathways that converge onto this transcription factor are considered (Bito et al. 1996). CREB is phosphorylated by many kinases other than PKA, including CAMKIV $\left(\mathrm{Ca}^{++}\right.$-calmodulin kinase IV), PKC (protein kinase $\mathrm{Ca}^{++}$dependent), CKI and CKII (casein kinases I and II) (Sheng et al. 1991; Shaywitz and Greenberg 1999). Also, an abundance of factors as diverse as peptide hormones, neurotransmitter systems, neuro-protective agents, and growth factors, such as BDNF and NGF regulate CREB gene expression and activation. Unmodified basal levels of CREB mRNA may, then, represent the net result of a series of redundant and compensatory processes.

The complexity of the regulation of CREB is further illustrated by a differential-splicing pattern of CREB among CNS regions suggesting a region-specific functional regulation of various CREB-isoforms (Pietruck et al. 1999). While no difference was observed in basal CREB levels, a difference was observed in the expression of the two isoforms of CREB. Expression levels of CREB- $\Delta$ were consistently four to five times higher than those of CREB- $\alpha$. These data are in line with earlier studies (Pietruck et al. 1999) that demonstrated a differential expression pattern of CREB isoforms in the central nervous system and where the CREB- $\Delta$ isoform was most abundant. A third isoform, CREB- $\beta$, has only been demonstrated in transgenic mice lacking both the $\alpha$ and $\Delta$ isoforms, and was therefore not considered in this study (Blendy et al.1996). 


\section{B}

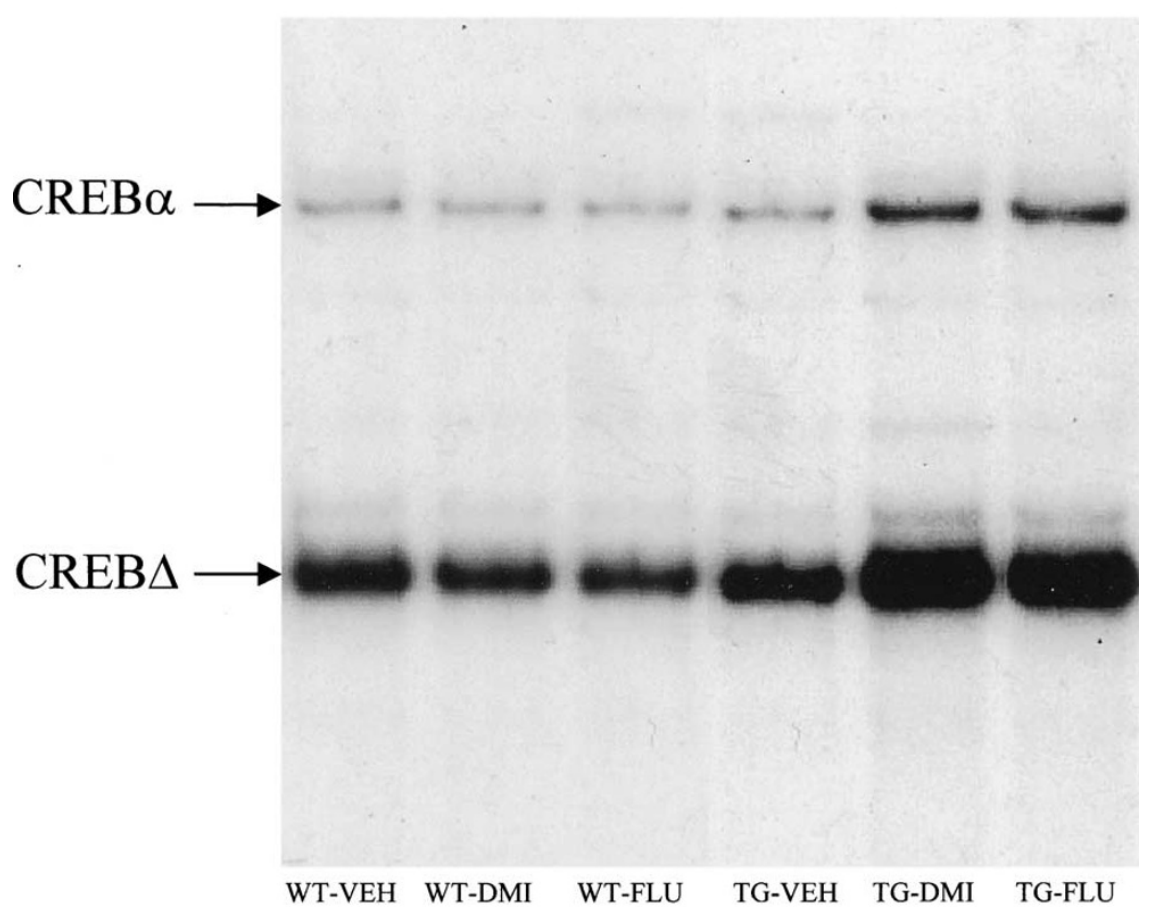

Figure 3. (Continued)

The second part of this study examined the influence of long-term antidepressant treatment on CREB expression. Desipramine and fluoxetine differentially affected CREB gene expression in WT as compared with TG mice. Chronic treatment with desipramine and fluoxetine enhanced the expression of CREB mRNA in the hippocampus of healthy non-transgenic mice. The fact that both drugs affect CREB expression in a similar way cannot be explained by their primary action on cell membrane receptors since fluoxetine is a typical selective serotonin reuptake inhibitor and desipramine is a less

Table 1. The Effect of Chronic Treatment with Fluoxetine and Desipramine on the Expression of CREB in WT and TG Mice

\begin{tabular}{lccccc}
\hline & \multicolumn{2}{c}{ WT } & & \multicolumn{2}{c}{ TG } \\
\cline { 2 - 3 } \cline { 5 - 6 } Tissue Type & FLU & DMI & & FLU & DMI \\
\hline Hippocampus & $\uparrow$ & $\uparrow$ & & $\uparrow$ & - \\
Cortex & - & - & & $\uparrow$ & $\uparrow$ \\
Striatum & - & - & & - & - \\
Cerebellum & - & - & & - & - \\
Hypothalamus & - & - & & - & - \\
\hline
\end{tabular}

$\uparrow=$ Significant induction of CREB gene expression after chronic exposure to fluoxetine (FLU) or desipramine (DMI) with respect to vehicle treated WT or TG mice.

$=$ No induction of CREB gene expression after chronic exposure to fluoxetine (FLU) or desipramine (DMI) with respect to vehicle treated WT or TG mice. selective norepinephrine reuptake inhibitor. Prolonged administration of various types of antidepressants also reduces the number of biogenic amine receptors and the mechanism underlying antidepressant-induced CREB upregulation is more likely to involve the activation of the intracellular signaling cascade downstream to early stimulation of the cAMP system.

In contrast, in the hippocampus of transgenic mice, the expression of CREB was enhanced only by chronic fluoxetine, but not by desipramine. The molecular mechanisms underlying this altered sensitivity in the expression of CREB in the hippocampus of transgenic mice are not yet known but evidence is accumulating, indicating that different classes of antidepressant drugs activate cAMP signal transduction at different points of the cascade (Frechilla et al. 1998; Takahashi et al. 1999; Popoli et al. 2000).

CREB activation is regulated by phosphorylation and there is substantial interaction between GR related signaling and the phosphorylation of CREB. GR prevents CREB phosphorylation by direct linking to the protein and hindering its binding to CRE. In addition, glucocorticoids can directly affect CREB function by interfering with the phosphorylation of CREB (Legradi et al. 1997). A significant difference in GR number and function in various cerebral areas characterize the transgenic mice used in this study, in the absence of significant elevations in peripheral corticosterone. This suggests that 
CREB and, presumably, other transcription factors, such as AP1, activated in these specific brain regions during antidepressant treatment may be influenced either directly by GR number and function or indirectly by the local availability of corticosterone.

Our results not only indicate a differential effect of chronic exposure to two different classes of antidepressant drugs on CREB expression but also imply a region-specific effect. While the expression of CREB in the hippocampus of WT mice was enhanced by chronic administration of both desipramine and fluoxetine, CREB mRNA levels in the cortex were not significantly affected by either antidepressant drug. Support for a selective region-specific effect of antidepressants on CREB expression is provided by a study using post-mortem tissue from patients suffering from major depression that showed CREB expression to be enhanced in the temporal, but not occipital, cortex after treatment with antidepressants (Dowlatshahi et al. 1998).

One explanation for the different expression patterns of CREB displayed by the cortex and hippocampus may be the upregulation of two CAMP specific phosphodiesterase isoforms, PDE4A and PDE4B, that were upregulated in the cortex but not in the hippocampus of rats after chronic antidepressant treatment (Fujimaki et al. 2000; Thome et al. 2000). Phosphodiesterases play a crucial role in converting cAMP to 5'-AMP, and inhibit the transduction pathway leading to the activation of CREB. As a consequence they diminish the responsiveness of CREB gene expression to antidepressant drugs, which seems to be mediated by an upregulation of the cAMP-signaling pathway. In contrast to the lack of effect of antidepressants on the regulation of CREB in the cortex of WT mice, both fluoxetine and desipramine significantly enhanced the expression of CREB in the cortex of transgenic mice. Enhanced responsiveness in the cortex of TG mice may, at least in part, be mediated by the expression and activity of phosphodiesterases. Induction of phosphodieaterases in the cortex is mediated by the cAMP/PKA related signaling pathway ( $\mathrm{Du}-$ man et al. 1999; Fujimaki et al. 2000). Given that substantial interactions exist between cAMP-PKA pathways and glucocorticoid signaling, it is thus possible that the impairment in GR function, characteristic of the transgenic mice used in this study, causes an altered sensitivity in cAMP-PKA induced gene transcription of specific phosphodiesterases. Moreover, an important role for phosphodiesterases in the mechanism of action of antidepressant drugs is suggested by preclinical and clinical studies that show phosphodiesterase inhibitors have antidepressant-like effects on behavior (O'Donnell 1993).

The reason for regional differences between fluoxetine and desipramine is not easy to explain. Both the hippocampus and the cortex receive elaborate projections from the NE and 5-HT systems. However, alternate signaling pathways or different susceptibilities to autoreg- ulation of these systems may cause, for example, more rapid inhibition of the 5-HT system in response to fluoxetine (Blier and de Montigny 1994). Selective sensitivity to fluoxetine in the cortex of transgenic mice corresponds to other studies where fluoxetine, but not desipramine, significantly increased $\beta$-galactosidase and the phosphorylation of CREB in rats (Thome et al. 2000).

In summary, these results support the hypotheses that expression of CREB may be an intracellular target of two different types of antidepressants in two brain areas known to be important sites for depression. The findings further indicate that, while in normal healthy animals, the effects of antidepressants on CREB gene expression depend on the specific brain structure, in transgenic mice CREB expression was more sensitive to the type of antidepressant and less dependent on the cerebral region.

A particular benefit of our model was that it allowed the study of long-term effects of an over-active HPAsystem on the regulation of cAMP-mediated gene transcription in vivo. We tested the hypothesis that disruption of GR gene expression, resulting in defective glucocorticoid feedback inhibition and dysregulation of HPA system activity result in abnormal CREB gene expression. Furthermore, the hypothesis was tested that the antidepressant drugs desipramine and fluoxetine, not only normalize HPA system function, but also affect CREB gene expression. Changes in CREB gene expression could explain both the time necessary for antidepressants to be therapeutically effective as well as their long-term effects. Given, however, that fluoxetine enhanced the expression of CREB both in cortex and hippocampus of transgenic mice while desipramine affected CREB expression only in the cortex, the signaling pathways activated by the two antidepressants leading to changes in CREB expression may not be the same. Conceptually, this suggests that altered neuroendocrine functioning may lead to a neuroanatomically selective vulnerability of the cAMP mediated signal transduction pathway and, as a consequence, may induce an enhanced sensitivity of cAMP mediated gene transcription to antidepressant treatment. These findings also suggest that HPA axismediated vulnerability and life-long central glucocorticoid receptor dysfunction can lead to differential effects of antidepressants on intracellular signal transduction pathways and the regulation of specific target genes including an altered sensitivity of CREB to the effects of antidepressants.

\section{ACKNOWLEDGMENTS}

We thank Dr. Schütz for kindly providing the CREB cDNA. The authors also thank Stefania Gibertini and Paolo Muzzioli for their assistance and Ivo Ibba for excellent technical support. 


\section{REFERENCES}

Barden N (1996): Modulation of glucocorticoid receptor gene expression by antidepressant drugs. Pharmacopsychiatry 29:12-22

Barden N, Reul JMHM, Holsboer F (1995): Do antidepressants stabilize mood through actions on the hypothalamus-pituitary-adrenocortical system? Trends Neurosci 18:6-11

Barden N, Stec ISM, Montkowski A, Holsboer F, Reul JMHM (1997): Endocrine profile and neuroendocrine challenge tests in transgenic mice expressing antisense RNA against the glucocorticoid receptor. Neuroendocrinology 66:212-220

Bito H, Deisseroth K, Tsien RW (1996): CREB phosphorylation and dephosphorylation: $\mathrm{C} \mathrm{Ca}^{2+}$ - and stimulus duration-dependent switch for hippocampal gene expression. Cell 87:1203-1214

Blendy JA, Kaestner KH, Schmid W, Gass P, Schutz G (1996): Targeting of the CREB gene leads to up-regulation of a novel CREB mRNA isoform. EMBO Journal 15:1098-1106

Blier P, de Montigny C (1994): Current advances and trends in the treatment of depression. Trends Pharm Sci 15:220-226

Chen ACH, Shirayama Y, Shin KH, Neve RL, Duman RS (2001): Expression of cAMP element binding protein (CREB) in hippocampus produces an antidepressant effect. Biol Psychiatry 49:753-762

Chomczynski P, Sacchi N (1987): Single step method of RNA isolation by guanidium thiocyanate chloroform extraction. Anal Biochem 162:156-159

Dijkstra I, Tilders FJH, Aguilera G, Kiss A, Rabadandiehl C, Barden N, Karanth S, Holsboer F, Reul JMHM (1998): Reduced activity of hypothalamic corticotropin-releasing hormone neurons in transgenic mice with impaired glucocorticoid receptor function. J Neuroscience 18: 3909-3918

Dowlatshahi D, MacQueen GM, Wang JF, Young LT (1998): Increased temporal cortex CREB concentrations and antidepressant treatment in major depression. Lancet 352:1754-1755

Duman RS, Heninger GR, Nestler EJ (1997): A molecular and cellular theory of depression. Arch Gen Psychiatry 54:597-606

Duman RS, Malberg J, Thome J (1999): Neural plasticity to stress and antidepressant treatment. Biol Psychiatry 46:1181-1191

Frechilla D, Otano A, Del Rio J (1998): Effect of chronic antidepressant treatment on transcription factor binding activity in rat hippocampus and frontal cortex. Progr Neuro-Psychopharmacol \& Biol Psychiatry 22:787-802

Fujimaki K, Morinobu S, Duman RS (2000): Administration of a cAMP phosphodiesterase 4 inhibitor enhances antidepressant-induction of BDNF mRNA in rat hippocampus. Neuropsychopharmacology 22:42-51

Ghosh A, Greenberg ME (1995): Calcium signaling in neurons: molecular mechanisms and cellular consequences. Science 268:239-247

Gonzalez GA, Montminy MR (1989): Cyclic AMP stimulates somatostatin gene transcription by phosphorylation of CREB at serine 133. Cell 59:675-680
Hatalski CG, Baram TZ (1997): Stress-induced transcriptional regulation in the developing rat brain involves increased cyclic adenosine 3',5'-monophosphate-regulatory element binding activity. Mol Endocrinol 11:2016-2024

Holsboer F, Barden N (1996): Antidepressants and hypothalamic pituitary adrenocortical regulation. Endocrine Rev 17:187-205

Holsboer F (2000): The Corticosteroid Receptor Hypothesis of Depression. Neuropsychopharmacology 23:477-501

Karanth S, Lindhorst AC, Stalla K, Barden N, Holsboer F, Reul JM (1997): Hypothalamic-pituitary-adrenocortical axis changes in a transgenic mouse model with impaired glucocorticoid receptor function. Endocrinology 138:34763485

Lamas M, Sassone-Corsi P (1997): The dynamics of the transcriptional response to cyclic adenosine $3^{\prime}, 5^{\prime}$-monophosphate: recurrent inducibility and refractory phase. Mol Endocrinol 11:1415-1424

Legradi G, Holzer D, Kapcala LP, Lechan RM (1997): Glucocorticoids inhibit stress-induced phosphorylation of CREB in corticotropin-releasing hormone neurons of the hypothalamic paraventricular nucleus. Neuroendocrinology 66:86-97

Meyer TE, Habener JF (1993): Cyclic adenosine 3',5'-monophosphate response element binding protein (CREB) and related transcription-activating deoxyribonucleic acid-binding proteins. Endocrine Rev 14:269-290

Montminy MR, Gonzalez GA, Yamamoto KK (1990): Regulation of cAMP-inducible genes by CREB. Trends Neurosci 13:184-188

Nestler EJ, Terwilliger RZ, Duman RS (1989): Chronic antidepressant administration alters the subcellular distribution of cyclic AMP-dependent protein kinase in rat frontal cortex. J Neurochem 53:1644-1647

Nibuya M, Nestler EJ, Duman RS (1996): Chronic antidepressant administration increases the expression of cAMP response element binding protein (CREB) in rat hippocampus. J Neurosci 16:2365-2372

O'Donnell JM (1993): Antidepressant-like effects of rolipram and other inhibitors of cyclic AMP phosphodiesterase on behavior maintained by differential reinforcement of low response rate. J Pharmacol Exp Ther 264:1168-1178

Ozawa H, Rasenick MM (1991): Chronic electroconvulsive treatment augments coupling of the GTP-binding protein Gs to the catalytic moiety of adenylyl cyclase in a manner similar to that seen with chronic antidepressant drugs. J Neurochem 56: 330-338.

Pariante CM, Miller AH (2001): Glucocorticoid receptors in major depression: relevance to pathophysiology and treatment. Biol Psychiatry 9:391-404

Pepin MC, Pothier F, Barden N (1992a): Impaired Type II glucocorticoid-receptor function in mice bearing antisense RNA transgene. Nature 355:725-728

Pepin MC, Pothier F, Barden N (1992b): Antidepressant drug action in a transgenic mouse model of the endocrine changes seen in depression. Mol Pharmacology 42:991-995

Pietruck C, Xie G-X, Sharma M, Meuser T, Pierce Palmer P (1999): Multiple splice patterns of cyclic AMP response element-binding protein mRNA in the central nervous system of the rat. Mol Brain Res 69:286-289 
Popoli M, Brunello N, Perez J, Racagni G (2000): Second messenger-regulated protein kinases in the brain: their functional role and the action of antidepressant drugs. J Neurochemistry 74:21-33

Sassone-Corsi P (1995): Transcription factors responsive to cAMP. Ann Rev Cell \& Dev Biol 11:355-377

Shaywitz AJ, Greenberg ME (1999): CREB: A stimulusinduced transcription factor activated by a diverse array of extracellular signals. Ann Rev Biochem 68:821-861

Shelton RC, Manier DH, Sulser F (1996): cAMP-dependent protein kinase activity in major depression. Am J Psychiatry 153:1037-1042
Sheng M, Thompson MA, Greenberg ME (1991): CREB: a $\mathrm{Ca}^{2+}$-regulated transcription factor phosphorylated by calmodulin-dependent kinases. Science 252:1427-1430

Takahashi M, Terwilliger R, Lane C, Mezes PS, Conti M, Duman R (1999): Chronic antidepressant administration increases the expression of cAMP-specific phosphodiesterase $4 \mathrm{~A}$ and $4 \mathrm{~B}$ isoform. J Neurosci 19:610618

Thome J, Sakai N, Shin K-H, Steffen C, Zhang Y-J, Impey S, Storm D, Duman RS (2000): cAMP response elementmediated gene transcription is upregulated by chronic antidepressant treatment. J Neurosci 20:4030-4036 